
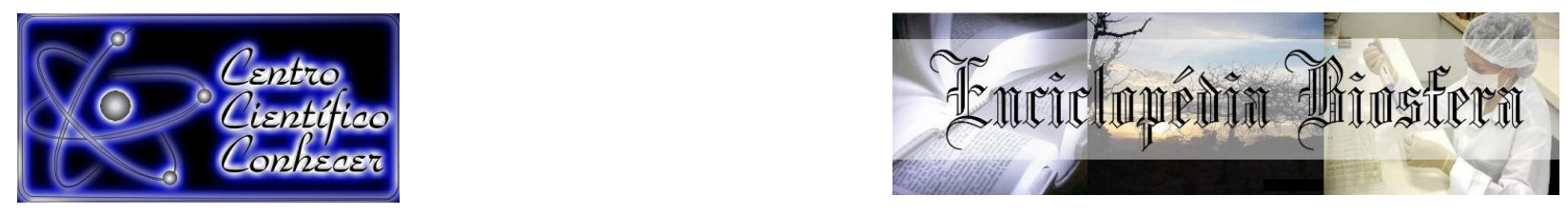

\title{
ATRIBUTOS QUÍMICOS DO SOLO E PRODUTIVIDADE DE MILHO CULTIVADO COM APLICAÇÃO DE CORRETIVOS E SISTEMAS DE MANEJO DO SOLO
}

Hassen Youssef Neto ${ }^{1}$, Ricardo Falqueto Jorge ${ }^{2}$, Cinara Xavier de Almeida ${ }^{2}$, Elias Nascentes Borges ${ }^{2}$, Renato Ribeiro Passos ${ }^{3}$

${ }^{1}$ Mestrando Universidade Federal de Uberlândia/Instituto de Ciências Agrárias ICIAG/UFU, (hassenruralpec@hotmail.com), Uberlândia, MG-Brasil

${ }^{2}$ Professor ICIAG/UFU, Monte Carmelo, MG-Brasil

${ }^{3}$ Professor Universidade Federal do Espírito Santo - Centro de Ciências Agrárias, Alegre, ES-Brasil

Recebido em: 08/04/2017 - Aprovado em: 10/06/2017 - Publicado em: 20/06/2017 DOI: 10.18677/EnciBio 2017A18

\begin{abstract}
RESUMO
O estudo da distribuição de nutrientes no perfil do solo é um método adequado para se detectar a influência dos sistemas de manejo do solo na aplicação de corretivos, bem como para avaliar o seu efeito na nutrição das plantas. Assim, objetivou-se avaliar os sistemas de manejo do solo e a aplicação de calcário e gesso sobre os atributos químicos do solo e a produtividade da cultura do milho. O experimento de campo foi realizado em um Latossolo Vermelho Distrófico típico no delineamento de blocos casualizados, no esquema fatorial, com quatro repetições, sendo cultivo convencional, mínimo e semeadura direta e a aplicação de calcário ou calcário e gesso. Foram realizadas análises químicas do solo e foliares da cultura do milho, bem como determinado a produtividade de grãos. Observou-se que os atributos químicos do solo, a nutrição mineral e a produtividade de grãos da cultura do milho sofreram influência dos sistemas de manejo, sendo que o tratamento utilizando cultivo convencional associado à aplicação de calcário e gesso agrícola apresentou os melhores resultados, indicando a necessidade da incorporação do corretivo para a recuperação do solo sob pastagem degradada.
\end{abstract}

PALAVRAS-CHAVE: ausência de preparo; calcário; cultivo convencional; cultivo mínimo; gesso agrícola.

\section{SOIL CHEMICAL ATTRIBUTES AND CORN PRODUCTIVITY CULTIVATED WITH SOIL CORRECTIVES APPLICATION AND SOIL MANAGEMENT SYSTEMS}

\begin{abstract}
The nutrients distribution study on the soil profile is an appropriate method to detect the influence of soil management systems in the correctives application, as well as to evaluate its effect on plant nutrition. Therefore, the aim of this study was to evaluate both the effect of soil management systems and the correctives application on soil chemical properties and grain yield of corn. A field experiment in a randomized split-plot, with four replications, installed on a Hapludox clay soil under conventional tillage, minimum tillage and no-tillage, with liming and gypsum application or just liming, was performed. Soil chemical analysis and foliar chemical analysis were performed, as well as the determination of corn grain yield. It was
\end{abstract}


observed that the soil chemical properties, mineral nutrition and corn grain yield were affected by management systems, and the treatment using conventional tillage associated with the liming and gypsum application presented the best results.

KEYWORDS: no-tillage; limestone; conventional tillage; minimum tillage; gypsum.

\section{INTRODUÇÃO}

O milho é uma cultura que tem diversas funções no mercado interno e externo, podendo ser considerado como um fator de equilíbrio no agronegócio. Devido à sua multiplicidade de aplicações, quer seja na alimentação humana, quer seja na alimentação animal, assume relevante papel socioeconômico, além de constituir-se em indispensável matéria-prima que impulsiona diversificados complexos agroindustriais (OZELAME \& ANDREATTA, 2013).

Diversas formas de manejo do solo têm sido estudadas para a condução do milho a campo, incluindo-se o revolvimento somente nas fileiras de semeadura ou o revolvimento total, pelo método de preparo convencional com aração e gradagens, apenas gradagens e com escarificação (MOREIRA et al. 2014).

A importância dos sistemas convencionais de manejo está relacionada à incorporação do calcário antes da instalação do sistema de semeadura direta para neutralizar a acidez em profundidade, que se mostra mais eficiente do que a aplicação superficial (KAMINSKI et al., 2005). Entretanto, a correção da acidez em profundidade, mediante a aplicação de calcário superficial em doses maiores do que as recomendadas pode causar desbalanceamento nutricional na superfície, já que a movimentação de bases poderá ser lenta e incerta, dependendo da quantidade de água, do calcário aplicado e do tipo de solo (COSTA \& CRUSCIOL, 2016).

Assim, os efeitos da calagem normalmente restringem-se às zonas de aplicação ou imediatamente abaixo delas (POTTKER \& BEN, 1998) e os valores de $\mathrm{pH}$ e $\mathrm{Al}$ do solo alteram-se pouco em profundidade devido à baixa solubilidade dos corretivos agrícolas de acidez e à alta reatividade de seus ânions com os ácidos presentes na camada em que o calcário é incorporado (KAMINSKI et al., 2005).

Conforme CAIRES (2013) e CASTRO \& CRUSCIOL (2015) ocorre efeito positivo da calagem em aumentar a produção e melhorar a absorção de nutrientes. Dessa forma, CASTRO \& CRUSCIOL (2013) trabalhando em um Latossolo Vermelho distroférrico, sob sistema de semeadura direta, observaram que a calagem aumentou a produtividade de milho.

O gesso agrícola, por outro lado, tem sido utilizado em solos ácidos como um produto complementar ao calcário, com o objetivo de diminuir a toxicidade do $\mathrm{Al} \mathrm{e}$ aumentar a concentração de Ca em profundidade (PAULETTI et al., 2014). A grande mobilidade vertical de cátions ocasionada pelo gesso deve-se à maior solubilidade desse produto em relação aos calcários, à inalteração das cargas elétricas, e à permanência do ânion sulfato quase que totalmente na solução do solo (CAIRES et al., 2004).

Nesse contexto, acredita-se ser possível corrigir o solo de cerrado sob pastagem com sinais de degradação, pela aplicação superficial de corretivos e condicionadores de solo. Assim, objetivou-se com este trabalho avaliar o efeito de métodos de manejo do solo e a aplicação de calcário e gesso sobre os atributos químicos do solo e a produtividade da cultura do milho, em área de cerrado. 


\section{MATERIAL E MÉTODOS}

O ensaio foi realizado no município de Uberlândia-MG, Fazenda do Glória (latitude $18^{\circ} 58^{\prime} 0,7^{\prime \prime S}$, longitude $48^{\circ} 12^{\prime} 24,6 " \mathrm{~W}$, e altitude de $830 \mathrm{~m}$ ). O solo da área experimental é um Latossolo Vermelho Distrófico típico (EMBRAPA, 2013), que nos últimos anos estava sendo utilizado com pastagem de brachiaria, que apresentava baixa capacidade de suporte animal e sinais de degradação. $\mathrm{O}$ clima predominante, segundo classificação de Köppen, é o Aw. A precipitação pluviométrica média é de $1.550 \mathrm{~mm}$ anuais, caracterizada por um período chuvoso de seis meses (outubro a março).

Antes da instalação do experimento foram coletadas amostras de solo nas camadas de $0-0,05,0,05-0,15$ e 0,15-0,30 m visando à caracterização química do solo (EMBRAPA, 2009), da área experimental (Tabela 1).

TABELA 1. Caracterização química e física do Latossolo Vermelho, nas camadas de 0-0,05, 0,05-0,15 e 0,15-0,30 m. Fazenda Experimental do Glória, Uberlândia-MG

\begin{tabular}{|c|c|c|c|}
\hline \multirow{2}{*}{ Atributo } & \multicolumn{3}{|c|}{ Camada (m) } \\
\hline & $0-0,05$ & $0,05-0,15$ & $0,15-0,30$ \\
\hline pH em água $(1: 2,5)$ & 5,10 & 5,00 & 4,70 \\
\hline Fósforo $\left(\mathrm{mg} \mathrm{kg}^{-1}\right)$ & 1,73 & 0,88 & 0,11 \\
\hline Potássio $\left(\mathrm{mg} \mathrm{kg}^{-1}\right)$ & 43,00 & 30,00 & 13,00 \\
\hline Cálcio $\left(\mathrm{cmol}_{\mathrm{c}} \mathrm{dm}^{-3}\right)$ & 1,23 & 0,50 & 0,10 \\
\hline Magnésio $\left(\mathrm{cmol}_{\mathrm{c}} \mathrm{dm}^{-3}\right)$ & 0,80 & 0,30 & 0,10 \\
\hline Enxofre $\left(\mathrm{mg} \mathrm{kg}^{-1}\right)$ & 12,00 & 17,00 & 20,00 \\
\hline Alumínio $\left(\mathrm{cmol}_{\mathrm{c}} \mathrm{dm}^{-3}\right)$ & 0,15 & 0,27 & 0,25 \\
\hline $\mathrm{H}+\mathrm{Al}\left(\mathrm{cmol}_{\mathrm{c}} \mathrm{dm}^{-3}\right)$ & 5,20 & 5,50 & 5,00 \\
\hline $\mathrm{S}\left(\mathrm{cmol}_{\mathrm{C}} \mathrm{dm}^{-3}\right)$ & 2,14 & 0,88 & 0,23 \\
\hline $\mathrm{t}\left(\mathrm{cmol}_{\mathrm{c}} \mathrm{dm}^{-3}\right)^{\prime}$ & 2,29 & 1,15 & 0,48 \\
\hline $\mathrm{T}\left(\mathrm{cmol}_{\mathrm{c}} \mathrm{dm}^{-3}\right)$ & 7,34 & 6,38 & 5,23 \\
\hline Carbono Orgânico Total $\left(\mathrm{g} \mathrm{kg}^{-1}\right)$ & 13,69 & 9,45 & 7,50 \\
\hline $\mathrm{V}(\%)$ & 29,15 & 13,79 & 4,40 \\
\hline Areia Grossa $\left(\mathrm{g} \mathrm{kg}^{-1}\right)$ & 271,00 & 236,00 & 241,00 \\
\hline Areia Fina $\left(\mathrm{g} \mathrm{kg}^{-1}\right)$ & 283,00 & 312,00 & 284,00 \\
\hline Silte $\left(\mathrm{g} \mathrm{kg}^{-1}\right)$ & 104,00 & 17,00 & 12,00 \\
\hline Argila $\left(\mathrm{g} \mathrm{kg}^{-1}\right)$ & 342,00 & 435,00 & 463,00 \\
\hline Densidade de Partículas $\left(\mathrm{kg} \mathrm{dm}^{-3}\right)$ & 2,65 & 2,69 & 2,74 \\
\hline Densidade do Solo $\left(\mathrm{kg} \mathrm{dm}^{-3}\right)$ & 1,41 & 1,47 & 1,47 \\
\hline Porosidade Total $\left(\mathrm{dm}^{3} \mathrm{dm}^{-3}\right)^{\prime}$ & 0,47 & 0,45 & 0,42 \\
\hline Resistência do solo à penetração (MPa) & 5,03 & 11,59 & 8,55 \\
\hline Umidade do solo $\left(\mathrm{kg} \mathrm{kg}^{-1}\right)$ & 0,05 & 0,09 & 0,11 \\
\hline
\end{tabular}

Foi também realizada uma amostragem do solo na camada de 0-0,20 m, para caracterização química do solo (EMBRAPA, 2009), para a avaliação da necessidade de calagem, gessagem e adubação química do solo, cujos resultados foram: $\mathrm{pH}$ $\left(\mathrm{H}_{2} \mathrm{O}\right): 5,2 ; \mathrm{P}: 1,0 \mathrm{mg} \mathrm{dm}^{-3} ; \mathrm{K}: 31,0 \mathrm{mg} \mathrm{dm}^{-3}$; Ca: $0,2 \mathrm{cmol}_{\mathrm{c}} \mathrm{dm}^{-3} ; \mathrm{Mg}: 0,1 \mathrm{cmol}_{\mathrm{c}} \mathrm{dm}^{-3} ; \mathrm{Al}:$ $0,6 \mathrm{cmol}_{\mathrm{c}} \mathrm{dm}^{-3}$; $\mathrm{H}+\mathrm{Al}: 4,0 \mathrm{cmol}_{\mathrm{c}} \mathrm{dm}^{-3}$; V\%: 8,7; Areia: $550,0 \mathrm{~g} \mathrm{~kg}^{-1}$; Silte: $30,0 \mathrm{~g} \mathrm{~kg}^{-1} \mathrm{e}$ Argila: $420,0 \mathrm{~g} \mathrm{~kg}^{-1}$. Com base nesses resultados foram calculadas as quantidades de calcário a ser aplicadas, pelo método da neutralização do $\mathrm{Al}^{3+}$ e da elevação dos teores de $\mathrm{Ca}^{2+}+\mathrm{Mg}^{2+}$ e a quantidade de gesso agrícola foi calculada com base na textura do solo (CFSEMG, 1999). 
O delineamento experimental empregado foi o de blocos ao acaso, com quatro repetições. Os tratamentos foram constituídos por três sistemas de manejo do solo: sistema de cultivo convencional (CC - aração e gradagem a 0,2 $\mathrm{m}$ de profundidade), sistema de semeadura direta (SD - ausência de preparo) e sistema de cultivo mínimo (CM - escarificação a 0,1 m de profundidade) e por duas formas de correção do solo: aplicação de gesso agrícola (Ges) e/ou calcário (Cal).

As parcelas, com 11,2 m de largura e 24,0 m de comprimento, foram divididas em duas subparcelas de $12,0 \mathrm{~m}$ de comprimento (11,2 $\mathrm{m}$ de largura). As parcelas $(11,2 \mathrm{~m} \times 24 \mathrm{~m})$ receberam os sistemas de manejo do solo, e as subparcelas (11,2 m x $12 \mathrm{~m})$, a aplicação de calcário e gesso agrícola (Cal+Ges) ou apenas Cal.

No CC, os corretivos foram incorporados com grade pesada (grade aradora com incorporação a 0,2 $\mathrm{m}$ de profundidade); no SD, a aplicação dos corretivos foi realizada na superfície do solo, e no $\mathrm{CM}$, utilizou-se o escarificador, incorporando parcialmente (com cinco hastes equidistantes a $0,2 \mathrm{~m}$ e incorporação a $0,1 \mathrm{~m}$ de profundidade) o calcário e o gesso agrícola.

As parcelas sob CM e sistema de SD foram dessecadas com o herbicida glyphosate $\left(480 \mathrm{~g} \mathrm{~L}^{-1}\right)$, na dosagem de $3 \mathrm{~L} \mathrm{ha}^{-1}$. A semeadura do milho, híbrido C-911 da Dekalb $^{\circledR}$, foi realizada utilizando-se semeadora SHM 17, com espaçamento entrelinhas de $0,80 \mathrm{~m}$ e cinco sementes por metro. A adubação de semeadura foi realizada com $366 \mathrm{~kg} \mathrm{ha}^{-1}$ do formulado 04-30-16, a qual correspondeu à aplicação de $15 \mathrm{~kg} \mathrm{ha}^{-1}$ de nitrogênio $(\mathrm{N}), 110 \mathrm{~kg} \mathrm{ha}^{-1}$ de Pentóxido de fósforo $\left(\mathrm{P}_{2} \mathrm{O}_{5}\right)$ e $59 \mathrm{~kg} \mathrm{ha}$ ${ }^{1}$ de óxido de potássio $\left(\mathrm{K}_{2} \mathrm{O}\right)$.

Os tratamentos também receberam a aplicação de $130 \mathrm{~kg} \mathrm{ha}^{-1}$ de $\mathrm{N}$ em cobertura. A fonte de $\mathrm{N}$ utilizada foi o sulfato de amônio. Foi também realizada uma adubação potássica de cobertura, na dose de $11 \mathrm{~kg} \mathrm{ha}^{-1}$ de $\mathrm{K}_{2} \mathrm{O}$, utilizando-se como fonte o cloreto de potássio.

Foram coletadas amostras do tecido vegetal, conforme recomendações da CFSEMG (1999) para cultura do milho e amostras de solo nas camadas de 0-0,05, $0,05-0,15$ e $0,15-0,30 \mathrm{~m}$, sendo quatro amostras simples por camada, para compor uma amostra composta em cada parcela, na época do pleno florescimento da cultura do milho. As amostras foram então enviadas ao laboratório para análise de macro e micronutrientes (solo e planta), conforme metodologia proposta por EMBRAPA (2009).

Foram colhidas as quatro linhas centrais de cada subparcela, desprezando-se um metro de cada extremidade, compreendendo uma área útil de $32,0 \mathrm{~m}^{2}$, para a avaliação da produtividade de grãos, sendo realizada a correção da umidade de grãos para $13 \%$. Os dados foram submetidos a análise de variância, e quando significativo as médias foram comparadas pelo teste de Tukey ao nível de $5 \%$ de probabilidade, por meio do programa Sisvar ${ }^{\circledR}($ FERREIRA, 2014).

\section{RESULTADOS E DISCUSSÃO}

Observando-se a Tabela 2 é possível verificar que os atributos químicos do solo $\mathrm{pH}$, cálcio $(\mathrm{Ca})$, magnésio $(\mathrm{Mg})$, fósforo $(\mathrm{P})$ e enxofre $(\mathrm{S})$ não diferiram na camada 0$0,05 \mathrm{~m}$, considerando a influência dos sistemas de manejo e a aplicação dos corretivos, a exceção do cálcio $(\mathrm{Ca})$ que teve maior concentração quando da aplicação de Cal +Gesso. Entretanto, os teores de potássio (K) e carbono orgânico total (COT) foram menores no solo sob cultivo convencional (CC), provavelmente devido a maior capacidade de infiltração de água do solo, lixiviando o potássio e devido a incorporação da matéria orgânica realizada pelo preparo, respectivamente. Em relação aos teores de alumínio $(\mathrm{Al})$ no solo $(0-0,05 \mathrm{~m})$, verificou-se que houve 
diferença entre o CC, e o sistema de semeadura direta (SD), o qual apresentou maior teor de Al. Já a acidez potencial $(\mathrm{H}+\mathrm{Al})$ foi maior no solo sob $\mathrm{CM}$ em relação ao $\mathrm{CC}$, contudo, o CC e o CM não diferiram do solo sob PD. Resultados similares em Latossolo Vermelho foram observados por CAIRES et al. (2004) e CASTRO \& CRUSCIOL (2013), que constataram que o calcário aplicado na superfície alterou as condições químicas do solo, principalmente na camada de 0-0,05 m (CAIRES et al., 2004).

TABELA 2. Atributos químicos do Latossolo Vermelho, nas camadas de $0-0,05$, 0,05-0,15 e 0,15-0,30 m, em sistemas de manejo e aplicação de corretivos. Fazenda Experimental do Glória, Uberlândia, MG

\begin{tabular}{|c|c|c|c|c|c|c|c|c|c|}
\hline \multirow{2}{*}{ Sistemas } & \multicolumn{3}{|c|}{ Camada 0-0,05 m } & \multicolumn{3}{|c|}{ Camada $0,05-0,15 \mathrm{~m}$} & \multicolumn{3}{|c|}{ Camada $0,15-0,30 \mathrm{~m}$} \\
\hline & Cal & Cal+Ges & Média & Cal & Cal+Ges & Média & Cal & Cal+Ges & Média \\
\hline \multicolumn{10}{|c|}{$\mathrm{pH}$ em água $(1: 2,5)$} \\
\hline $\mathrm{CC}$ & 6,0 & 6,3 & $6,2 a$ & 5,6 & 6,0 & $5,8 a$ & 5,5 & 5,5 & $5,5 a$ \\
\hline CM & 5,8 & 5,9 & $5,9 a$ & 4,9 & 4,7 & $4,8 b$ & 4,9 & 4,7 & $4,8 b$ \\
\hline SD & 5,8 & 6,1 & 6,0 a & 4,7 & 4,8 & $4,8 b$ & 4,8 & 4,8 & $4,8 b$ \\
\hline Média & $5,9 A$ & $6,1 \mathrm{~A}$ & & $5,1 \mathrm{~A}$ & $5,2 \mathrm{~A}$ & & $5,1 \mathrm{~A}$ & $5,0 \mathrm{~A}$ & \\
\hline \multicolumn{10}{|c|}{ Cálcio $\left(\mathrm{cmol}_{\mathrm{c}} \mathrm{dm}^{-3}\right)$} \\
\hline $\mathrm{CC}$ & 1,72 & 1,91 & $1,82 a$ & 1,42 & 1,80 & $1,61 a$ & 1,04 & 1,30 & $1,17 a$ \\
\hline CM & 1,54 & 1,80 & $1,67 a$ & 0,32 & 0,32 & $0,32 b$ & 0,27 & 0,35 & $0,31 b$ \\
\hline SD & 1,35 & 2,20 & $1,78 a$ & 0,28 & 0,32 & $0,30 \mathrm{~b}$ & 0,22 & 0,47 & $0,35 b$ \\
\hline Média & $1,54 B$ & $1,97 A$ & & $0,67 A$ & $0,81 \mathrm{~A}$ & & $0,51 B$ & $0,71 \mathrm{~A}$ & \\
\hline \multicolumn{10}{|c|}{ Magnésio $\left(\mathrm{cmol}_{\mathrm{c}} \mathrm{dm}^{-3}\right)$} \\
\hline $\mathrm{CC}$ & 1,06 & 1,11 & $1,09 a$ & 0,95 & 1,02 & $0,99 a$ & 0,85 & 0,84 & $0,85 a$ \\
\hline CM & 1,01 & 0,98 & $1,00 a$ & 0,45 & 0,47 & $0,46 b$ & 0,28 & 0,29 & $0,29 b$ \\
\hline SD & 1,03 & 1,42 & $1,22 a$ & 0,36 & 0,42 & $0,39 \mathrm{~b}$ & 0,29 & 0,36 & $0,33 b$ \\
\hline Média & $1,03 \mathrm{~A}$ & $1,17 A$ & & $0,59 A$ & $0,64 \mathrm{~A}$ & & $0,47 A$ & $0,50 A$ & \\
\hline \multicolumn{10}{|c|}{ Fósforo $\left(\mathrm{mg} \mathrm{dm}^{-3}\right)$} \\
\hline $\mathrm{CC}$ & 2,89 & 3,75 & $3,32 a$ & 1,62 & 2,30 & $1,96 a$ & 1,13 & 1,55 & $1,34 a$ \\
\hline CM & 3,29 & 7,26 & $5,28 a$ & 1,12 & 1,24 & $1,18 b$ & 0,78 & 1,04 & $0,91 b$ \\
\hline SD & 5,57 & 8,21 & $6,89 a$ & 1,07 & 1,37 & $1,22 b$ & 0,75 & 0,87 & $0,81 b$ \\
\hline Média & $3,92 \mathrm{~A}$ & $6,41 \mathrm{~A}$ & & $1,27 B$ & $1,64 \mathrm{~A}$ & & $0,89 B$ & $1,15 A$ & \\
\hline \multicolumn{10}{|c|}{ Potássio $\left(\mathrm{mg} \mathrm{dm}^{-3}\right)$} \\
\hline $\mathrm{CC}$ & 39 & 34 & $37 b$ & 29 & 26 & $28 b$ & 27 & 23 & $25 b$ \\
\hline CM & 44 & 43 & $44 a$ & 35 & 31 & $33 a$ & 29 & 28 & $29 a$ \\
\hline SD & 44 & 43 & $44 a$ & 33 & 31 & $32 a$ & 26 & 31 & $29 a$ \\
\hline Média & $42 A$ & $40 \mathrm{~A}$ & & $32 A$ & $29 B$ & & $27 A$ & $24 B$ & \\
\hline \multicolumn{10}{|c|}{ Enxofre $\left(\mathrm{mg} \mathrm{dm}^{-3}\right)$} \\
\hline $\mathrm{CC}$ & 22 & 14 & $18 a$ & 66 & 46 & $56 a$ & 53 & 71 & $62 a$ \\
\hline CM & 40 & 23 & $32 a$ & 49 & 86 & $68 a$ & 56 & 91 & $74 a$ \\
\hline $\mathrm{AP}$ & 25 & 19 & $22 a$ & 85 & 66 & $76 a$ & 74 & 83 & $79 a$ \\
\hline Média & $29 A$ & $19 A$ & & $67 A$ & $66 A$ & & $61 \mathrm{~A}$ & $82 A$ & \\
\hline \multicolumn{10}{|c|}{ Alumínio $\left(\mathrm{cmol}_{\mathrm{c}} \mathrm{dm}^{-3}\right)$} \\
\hline $\mathrm{CC}$ & 0,02 & 0,01 & $0,02 b$ & 0,16 & 0,09 & $0,13 b$ & 0,25 & 0,21 & $0,23 b$ \\
\hline CM & 0,06 & 0,10 & $0,08 a b$ & 0,78 & 0,72 & $0,75 a$ & 0,68 & 0,73 & $0,70 a$ \\
\hline SD & 0,16 & 0,05 & $0,10 a$ & 0,89 & 0,74 & $0,82 a$ & 0,78 & 0,53 & $0,65 a$ \\
\hline Média & $0,08 \mathrm{~A}$ & $0,05 B$ & & $0,61 \mathrm{~A}$ & $0,52 A$ & & $0,57 \mathrm{~A}$ & $0,49 A$ & \\
\hline \multicolumn{10}{|c|}{$\mathrm{H}+\mathrm{Al}\left(\mathrm{cmol}_{\mathrm{c}} \mathrm{dm}^{-3}\right)$} \\
\hline $\mathrm{CC}$ & 2,44 & 2,05 & $2,25 b$ & 3,00 & 2,26 & $2,63 b$ & 3,20 & 2,58 & $2,89 b$ \\
\hline CM & 2,86 & 2,66 & $2,76 a$ & 4,24 & 4,44 & $4,34 a$ & 4,43 & 4,26 & 4,34 a \\
\hline SD & 2,94 & 2,38 & $2,66 a b$ & 4,60 & 4,04 & $4,32 a$ & 4,71 & 3,88 & $4,30 a$ \\
\hline Média & $2,75 \mathrm{~A}$ & $2,36 B$ & & $3,95 \mathrm{~A}$ & $3,58 \mathrm{~A}$ & & $4,11 \mathrm{~A}$ & $3,57 B$ & \\
\hline \multicolumn{10}{|c|}{ Carbono orgânico total $\left(\mathrm{g} \mathrm{kg}^{-1}\right)$} \\
\hline $\mathrm{CC}$ & 16,32 & 13,52 & $14,92 b$ & 16,27 & 13,84 & $15,05 a$ & 14,59 & 12,73 & $13,66 a$ \\
\hline CM & 17,26 & 16,53 & $16,89 a$ & 14,24 & 13,63 & $13,93 a b$ & 13,83 & 12,88 & $13,36 a$ \\
\hline SD & 17,07 & 16,76 & 16,92 a & 14,15 & 13,21 & $13,68 b$ & 13,92 & 12,28 & $13,10 a$ \\
\hline Média & $16,8 \mathrm{~A}$ & $15,6 B$ & & $14,9 \mathrm{~A}$ & $13,6 B$ & & $14,1 \mathrm{~A}$ & $12,6 B$ & \\
\hline
\end{tabular}

CC: cultivo Convencional; CM: cultivo Mínimo; SD: semeadura direta; Cal: calcário; Cal+Ges; calcário+gesso. Letras maiúsculas, na linha, comparam os corretivos; letras minúsculas, na coluna, comparam os sistemas de preparo do solo. Médias seguidas de letras iguais não diferem entre si pelo teste de Tukey ao nível de $5 \%$ de probabilidade. 
Para as camadas de 0,05-0,15 e 0,15-0,30 m, o CC proporcionou valores superiores de $\mathrm{pH}, \mathrm{Ca}, \mathrm{Mg}$ e $\mathrm{P}$, em relação ao $\mathrm{CM}$ e ao $\mathrm{SD}$, devido provavelmente a maior mobilização do solo. Esses resultados estão também relacionados à maior dose do(s) corretivo(s) aplicado(s) (calcário e/ou gesso). De maneira semelhante, CAIRES et al. (2004) constataram, em um Latossolo Vermelho distrófico de textura argilosa, que a correção da acidez pela calagem na superfície, com ou sem parcelamento, foi mais acentuada na camada superficial do solo $(0-0,05 \mathrm{~m})$ e que houve maior reação nas profundidades de 0,05-0,10 e 0,10-0,20 m, quando o calcário foi incorporado, corroborando os resultados. SOUZA et al. (2012) também observaram que o sistema de semeadura direta promoveu aumento de $\mathrm{Ca}$ nas camadas superficiais.

Os teores de $S$ não diferiram entre os sistemas de manejo e corretivos. $O$ fato da associação de calcário e gesso (Cal+Ges) não ter proporcionado valores superiores de enxofre no solo em relação à utilização somente de calcário, deve-se possivelmente à utilização de sulfato de amônio, que contém 22 a $24 \%$ de S em sua composição, como cobertura nitrogenada na cultura do milho. Corroboram com observações semelhantes os resultados obtidos por POTTKER \& BEN (1998).

Em consonância com os valores de $\mathrm{pH}, \mathrm{Ca}$ e $\mathrm{Mg}$, os valores de $\mathrm{Al} \mathrm{e} \mathrm{H}+\mathrm{Al}$ foram inferiores no $\mathrm{CC}$, em relação aos outros sistemas de preparo, nas camadas 0,05-0,15 e 0,15-0,30 m, indicando que a ação dos corretivos restringiu-se à superfície do solo, em função da não incorporação dos corretivos no CM e no SD, ao contrário do CC, em que houve incorporação dos mesmos. No entanto, CRUSCIOL et al. (2016) observaram, em Latossolo Vermelho distroférrico de Botucatu, sob esquemas de rotação e pastagem em SD, que aplicação de corretivo promoveu melhorias químicas no solo até à profundidade de $0,60 \mathrm{~m}$.

Observou-se que a aplicação de Cal+Ges elevou os teores de $\mathrm{Ca}$, na camada de $0,15-0,30 \mathrm{~m}$, e de $P$, nas acamadas de 0,05-0,15 e 0,15-0,30 m, em relação aos tratamentos que receberam apenas $\mathrm{Cal}$, sendo que esses apresentaram maior $\mathrm{H}+\mathrm{Al}$ na camada mais profunda do solo. Nesse sentido, ZANDONÁ et al. (2015), estudando a influência do gesso combinado com o calcário nos atributos do solo, constataram que houve aumento da saturação de bases em superfície e em profundidade, diminuição dos teores de Al no perfil do solo, corroborando os resultados obtidos neste trabalho.

Os resultados relacionados à nutrição mineral do milho mostram que houve aumento nos teores foliares dos macronutrientes $\mathrm{K}$, Ca e $\mathrm{Mg}$ no $\mathrm{CC}$ em relação aos demais sistemas de manejo (Tabela 3). Em relação aos teores de $\mathrm{N}$ e $\mathrm{P}$, não houve diferença entre o CC e CM. Entretanto, para o S, menores teores foliares foram observados no CC, em relação aos demais sistemas. Por outro lado, a aplicação associada de Cal+Ges favoreceu para que ocorressem maiores concentrações de $P$ e Ca na folha. CAIRES et al. (2004) observaram que a aplicação de gesso aumentou os teores foliares de N, K e Ca na cultura do milho, assim como, MICHALOVICZ et al. (2014) constataram elevação nos teores foliares de Ca e S, nas culturas do milho e da cevada. Entretanto, tanto CAIRES et al. (2004) quanto MICHALOVICZ et al. (2014) verificaram redução nos teores de $\mathrm{Mg}$, no tecido foliar do milho. 
TABELA 3. Teores foliares de macro e micronutrientes na cultura do milho cultivado em sistemas de manejo do solo e aplicação de corretivos. Fazenda Experimental do Glória, Uberlândia-MG

\begin{tabular}{|c|c|c|c|c|c|c|c|c|c|c|c|c|}
\hline \multirow{2}{*}{ Sistemas } & \multirow{2}{*}{\multicolumn{4}{|c|}{$\begin{array}{c}\text { Cal Cal+Ges Média } \\
\text { Nitrogênio }\left(\mathrm{g} \mathrm{kg}^{-1}\right)\end{array}$}} & Cal & $\mathrm{Cal}+\mathrm{Ge}$ & es $M$ & édia & Cal & Calt+ & + Ges & Média \\
\hline & & & & & \multicolumn{4}{|c|}{ Fósforo $\left(\mathrm{g} \mathrm{kg}^{-1}\right)$} & \multicolumn{4}{|c|}{ Potássio $\left(\mathrm{g} \mathrm{kg}^{-1}\right)$} \\
\hline CC & & 5,5 & 26,4 & $26,0 a$ & 1,41 & 1,65 & &, $5 a$ & 36 & & 36 & $36 a$ \\
\hline CM & & 4,8 & 23,7 & $24,3 a$ & 1,34 & 1,53 & & $4 a b$ & 32 & & 33 & $32 b$ \\
\hline SD & & 1,3 & 20,2 & $20,8 b$ & 1,23 & 1,39 & & $3 b$ & 31 & & 30 & $30 \mathrm{~b}$ \\
\hline \multirow[t]{2}{*}{ Média } & & $9 \mathrm{~A}$ & $23,4 \mathrm{~A}$ & & $1,33 B$ & 1,52 & & & $33 A$ & & 32 A & \\
\hline & \multicolumn{4}{|c|}{ Cálcio $\left(\mathrm{g} \mathrm{kg}^{-1}\right)$} & \multicolumn{4}{|c|}{ Magnésio $\left(\mathrm{g} \mathrm{kg}^{-1}\right)$} & \multicolumn{4}{|c|}{ Enxofre $\left(\mathrm{g} \mathrm{kg}^{-1}\right)$} \\
\hline $\mathrm{CC}$ & &, 94 & 4,83 & $4,4 a$ & 2,79 & 2,69 & & $7 a$ & 2,30 & & 2,05 & $2,2 b$ \\
\hline $\mathrm{CM}$ & & 86 & 3,78 & $3,3 b$ & 1,50 & 1,59 & & $5 \mathrm{~b}$ & 2,79 & & 3,28 & $3,0 a$ \\
\hline SD & &, 93 & 3,91 & $3,4 b$ & 1,45 & 1,39 & & $4 \mathrm{~b}$ & 2,50 & & 3,03 & $2,8 a$ \\
\hline Média & & $2 B$ & $4,2 A$ & & $1,9 A$ & $1,9 \mathrm{~A}$ & & & $2,5 \mathrm{~A}$ & & $2,8 \mathrm{~A}$ & \\
\hline \multirow{2}{*}{ Sistemas } & \multicolumn{3}{|c|}{ Ferro $\left(\mathrm{mg} \mathrm{kg}^{-1}\right)$} & \multicolumn{3}{|c|}{ Manganês $\left(\mathrm{mg} \mathrm{kg}^{-1}\right)$} & \multicolumn{3}{|c|}{ Cobre $\left(\mathrm{mg} \mathrm{kg}^{-1}\right)$} & \multicolumn{3}{|c|}{ Zinco $\left(\mathrm{mg} \mathrm{kg}^{-1}\right)$} \\
\hline & Cal & $\mathrm{Cal+}$ & Ges Média & Cal & Cal+Ges & Média & $\mathrm{Cal}$ & $\mathrm{Cal}+\mathrm{Ge}$ & Média & Cal & $\mathrm{Cal}+\mathrm{C}$ & es Média \\
\hline $\mathrm{CC}$ & 165 & & $\begin{array}{ll}55160 a \\
\end{array}$ & 39 & 48 & $43 a b$ & 11 & 14 & $13 a$ & 27 & 2 & $26 a$ \\
\hline CM & 121 & & $121 b$ & 49 & 50 & $50 a$ & 9 & 10 & $10 \mathrm{~b}$ & 26 & 2 & $25 a$ \\
\hline SD & 121 & & $126 b$ & 37 & 43 & $40 \mathrm{~b}$ & 8 & 11 & $10 \mathrm{~b}$ & 24 & 2 & $24 a$ \\
\hline Média & $136 \mathrm{~A}$ & 13 & $6 A$ & $42 B$ & $47 A$ & & $9 B$ & $12 A$ & & $26 A$ & 23 & \\
\hline
\end{tabular}

CC: cultivo convencional; $C M$ : cultivo Mínimo; SD: semeadura direta; Cal: calcário; Cal+Ges; calcário+gesso. Letras maiúsculas, na linha, comparam os corretivos; letras minúsculas, na coluna, comparam os sistemas de preparo do solo. Médias seguidas de letras iguais não diferem entre si pelo teste de Tukey ao nível de $5 \%$ de probabilidade.

Em relação aos micronutrientes, o CC apresentou teores foliares mais elevados de ferro $(\mathrm{Fe})$ e cobre $(\mathrm{Cu})$, em relação aos demais sistemas de manejo do solo. Para o manganês $(\mathrm{Mn})$ houve diferença apenas entre o $\mathrm{CM}$ e o SD. Ao contrário, os sistemas não influenciaram os teores de zinco (Zn). Contudo, a aplicação conjunta de Cal + Ges propiciou maiores teores de $\mathrm{Mn}$ e Cu e inferiores de $\mathrm{Zn}$.

O CC proporcionou maior produtividade de milho $\left(7,40 \mathrm{Mg} \mathrm{ha}^{-1}\right)$ em relação ao CM (5,16 Mg ha-1) e ao SD (4,49 Mg ha-1), corroborando os resultados obtidos por SECCO et al. (2009), que constataram que a escarificação do solo aumentou a produtividade de grãos da cultura do milho em relação aos solos compactados. Resultados semelhantes são observados no inicio dos sistemas em SD, contudo foram observados por CASTRO \& CRUSCIOL (2013), que no SD, os tratamentos sem incorporação do calcário mostraram produtividades de milho satisfatórias em relação aos tratamentos com incorporação do calcário. POTTKER \& BEN (1998) avaliando a resposta de algumas culturas a calcário aplicado na superfície de solos (semeadura direta) com $380 \mathrm{~g} \mathrm{~kg}^{-1}$ de argila e com $580 \mathrm{~g} \mathrm{~kg}^{-1}$ de argila, observaram que para trigo, milho e aveia, não foram observadas diferenças entre os tratamentos, havendo diferença somente para a soja, em que todos os tratamentos que receberam calcário aumentaram, em termos absolutos, o produtividade de grãos.

A produtividade nos tratamentos envolvendo a aplicação conjunta de Cal+Ges foi superior $\left(5,98 \mathrm{Mg} \mathrm{ha}^{-1}\right)$ à verificada somente com a utilização de Cal $\left(5,38 \mathrm{Mg} \mathrm{ha}^{-}\right.$ 1). De maneira semelhante, CAIRES et al. (2004) e ZANDONÁ et al. (2015) observaram que a produção do milho foi positivamente influenciada pela aplicação combinada de gesso e calcário, e afirmam que o incremento de Ca é um dos fatores determinantes para esse resultado. 


\section{CONCLUSÃO}

Os atributos químicos do solo e produtividade de grãos da cultura do milho sofrem influência dos sistemas de manejo.

O sistema de cultivo convencional associado à aplicação de calcário e gesso agrícola, incorporado com grade pesada, apresenta os melhores resultados para recuperar quimicamente o solo sob pastagem, visando integração agricultura pecuária em Latossolo Vermelho distrófico.

\section{REFERÊNCIAS}

CAIRES, E. F. Correção da acidez do solo em sistemas plantio direto. Piracicaba-SP: International Plant Nutrition Istitute (INPI), 2013. 13 p. (Informações agronômicas, n. 141).

CAIRES, E. F.; KUSMAN, M. T.; BARTH, G.; GARBUIO, F. J.; PADILHA, J. M. Alterações químicas do solo e resposta do milho à calagem e aplicação de gesso. Revista Brasileira de Ciência do Solo, Viçosa, v.28, n.1, p.125-136, 2004. Disponível em: http://dx.doi.org/10.1590/S0100-06832004000100013

CASTRO, G. S. A.; CRUSCIOL, C. A. C. Effects of surface application of dolomitic limestone and calcium-magnesium silicate on soybean and maize in rotation with green manure in a tropical region. Bragantia, v.74, n.3, p.311-321, 2015. Disponível em: https://dx.doi.org/10.1590/1678-4499.0346

CASTRO, G. S. A.; CRUSCIOL, C. A. C. Produtividade e nutrição mineral de soja, milho e capim-ruziziensis influenciados por calcário e escória de siderurgia. Pesquisa agropecuária brasileira, Brasília, v.48, n.6, p.673-681, 2013. Disponível em: http://dx.doi.org/10.1590/S0100-204X2013000600013

CFSEMG - COMISSÃO DE FERTILIDADE DO SOLO DO ESTADO DE MINAS GERAIS. Recomendações para o uso de corretivos e fertilizantes em Minas Gerais. 5ª Aproximação. Viçosa: UFV, 1999. 359p.

COSTA, C.H.M.; CRUSCIOL, C.A.C. Long-term effects of lime and phosphogypsum application on tropical no-till soybean-oat-sorghum rotation and soil chemical properties. European Journal of Agronomy, V.74, 119-132, 2016. Disponível em: http://dx.doi.org/10.1016/j.eja.2015.12.001

CRUSCIOL, C.A.C. et al. Annual crop rotation of tropical pastures with no-till soil as affected by lime surface application. European Journal of Agronomy, v.80, p.88104, 2016. Disponível em: http://dx.doi.org/10.1016/j.eja.2016.07.002

EMBRAPA - EMPRESA BRASILEIRA DE PESQUISA AGROPECUÁRIA. Manual de análises químicas de solos, plantas e fertilizantes. 2.ed. Brasília: Informação Tecnológica, 2009. 628p.

EMBRAPA - Empresa Brasileira de Pesquisa Agropecuária. Centro Nacional de Pesquisa de Solos. Sistema brasileiro de classificação de solos. Rio de Janeiro, 2013. $353 \mathrm{p}$.

FERREIRA, D. F. Sisvar: a Guide for its Bootstrap procedures in multiple comparisons. Ciência e Agrotecnologia. 2014, vol.38, n.2 p. 109-112. Disponível em: http://dx.doi.org/10.1590/S1413-70542014000200001. 
KAMINSKI, J.; RHEINHEIMER, S. D.; GATIBONI, C. L.; BRUNETTO, G.; SILVA, L. $S$. Eficiência da calagem superficial e incorporada precedendo o sistema plantio direto em um argissolo sob pastagem natural. Revista Brasileira de Ciência do Solo, Viçosa, v.29, n.4, p.573-580, 2005. Disponível em: http://dx.doi.org/10.1590/S0100-06832005000400010

MICHALOVICZ, L. et al. Soil fertility, nutrition and yield of maize and barley with gypsum application on soil surface in no-till. Revista Brasileira de Ciência do Solo, Viçosa, v.38, n.5, p.1496-1505, 2014. Disponível em: http://dx.doi.org/10.1590/S0100-06832014000500015

MOREIRA, F. R.; DECHEN, S. C. F.; SILVA, A. P.; FIGUEIREDO, G. C.; MARIA, I. C.; TEREZINHA, $P$. Intervalo hídrico ótimo em um Latossolo vermelho cultivado em sistema semeadura direta por 25 anos. Revista Brasileira de Ciência do Solo, v.38, n.1, p.118-127, 2014. Disponível em: http://dx.doi.org/10.1590/S010006832014000100011

OZELAME, O.; ANDREATTA, T. A produção de cereais em uma propriedade no município de Chapecó-SC. Ciência Rural, Santa Maria, v.43, n.2, p.212-218, 2013. Disponível em: http://dx.doi.org/10.1590/S0103-84782013000200004

PAULETTI, V.; PIERRI, L.; RANZAN, T.; BARTH, G.; MOTTA, A. C. V. Efeitos em longo prazo da aplicação de gesso e calcário no sistema de plantio direto. Revista Brasileira de Ciência do Solo, Viçosa, v.38, n.2, p.495-505, 2014. Disponível em: http://dx.doi.org/10.1590/S0100-06832014000200014

POTTKER, D.; BEN, J. R. Calagem para uma rotação de culturas no sistema plantio direto. Revista Brasileira de Ciência do Solo, Viçosa, v.22, n.4, p.675-684, 1998. Disponível em: http://dx.doi.org/10.1590/S0100-06831998000400013

SECCO, D.; REINERT, D. J.; REICHERT, J. M. Vanderlei Rodrigues da Silval Atributos físicos e rendimento de grãos de trigo, soja e milho em dois Latossolos compactados e escarificados. Ciência Rural, Santa Maria, v.39, n.1, 2009. Disponível em: http://dx.doi.org/10.1590/S0103-84782009000100010

SOUZA, F. R.; ROSA JUNIOR, E. J.; FIETZ, C. R.; BERGAMIN, A. C.; ROSA, Y. B. C. J.; ZEVIANI, W. M. Efeito do gesso nas propriedades químicas do solo sob dois sistemas de manejo. Semina: Ciências Agrárias, v.33, n.5, p.1717-1732, 2012. Disponível em: https://dx.doi.org/10.5433/1679- 0359.2012v33n5p1717

ZANDONÁ, R. R.; BEUTLER, A. N.; BURG, G. M.; BARRETO, C. F.; SCHMIDT, M. $\mathrm{R}$. Gesso e calcário aumentam a produtividade e amenizam o efeito do déficit hídrico em milho e soja. Pesquisa Agropecuária Tropical, v.45, n.2, p.128-137, 2015. Disponível em: https://dx.doi.org/10.1590/1983-40632015v4530301 